\title{
Appendicular Abscess Revealing Gastrointestinal Stromal Tumor of the Appendix
}

\author{
Lalaina Nomenjanahary ${ }^{1}$, Zo Irène Raivoherivony¹, Adriana Tongavelona1, \\ Randrianjafisamindrakotroka Nantenaina Soa ${ }^{2}$ \\ ${ }^{1}$ Department of Pathology, Joseph Ravoahangy Andrianavalona University Hospital, Antananarivo, Madagascar \\ ${ }^{2}$ Chairman at the Department of Pathology, Medical School of Antananarivo, Antananarivo, Madagascar \\ Email: zoraivoherivony@yahoo.fr
}

How to cite this paper: Nomenjanahary, L., Raivoherivony, Z.I., Tongavelona, A. and Soa, R.N. (2021) Appendicular Abscess Revealing Gastrointestinal Stromal Tumor of the Appendix. Open Journal of Pathology, $11,115-119$.

https://doi.org/10.4236/ojpathology.2021.1 $\underline{14011}$

Received: September 11, 2021

Accepted: October 25, 2021

Published: October 28, 2021

Copyright $\odot 2021$ by author(s) and Scientific Research Publishing Inc. This work is licensed under the Creative Commons Attribution International License (CC BY 4.0).

http://creativecommons.org/licenses/by/4.0/

\begin{abstract}
Gastrointestinal stromal tumor (GIST) is a rare tumor of the digestive tract, but it is the most common of the mesenchymal tumors. The location is often gastric and small intestine. GIST of the appendix is extremely rare. We report one case in a 48-year-old man. He complained of severe pain in the right iliac region. The clinical presentation was typically like acute appendicitis. Abdominal ultrasound was performed and suspected an appendicular abscess. Surgical excision of the appendix was performed and histological diagnosis was "gastrointestinal stromal tumor of the appendix".
\end{abstract}

\section{Keywords}

GIST, Appendix, Pathology, Antananarivo

\section{Introduction}

Gastrointestinal stromal tumor (GIST) is a mesenchymal tumor of the digestive tract, derived from Cajal cells that express the proto-oncogene c-Kit. It is a rare tumor but the most common of the digestive mesenchymal tumors. It is most often localized in the stomach and rarely in the small intestine. The appendicular site is exceptional. Few cases are reported in the literature. Appendicular GIST can manifest in different forms, but the clinical examination finds always appendicitis-like symptoms.

We report a case of appendicular GIST manifested as an appendicular acute, and with the literature review to determine the characteristics of this rare lesion.

\section{Observation}

It was a 48-year-old man referred to the emergency for severe pain in the right 
iliac region. The disease would have started a month ago with repeated abdominal pain which increased in intensity and became transfixing.

On clinical examination, there was a tenderness abdomen in the right iliac region, without a palpable mass.

The biological examinations concluded an inflammatory syndrome.

Abdominal ultrasound showed an enlarged appendix with an abscess and the other abdominal organs appeared normal.

Appendectomy was performed urgently. On gross examination, the specimen was firm and beige, measuring $8 \times 7 \times 5 \mathrm{~cm}$. The mucosa was ulcerated, and there was a whitish, fasciculated mass, measuring $5 \times 4 \times 3 \mathrm{~cm}$, infiltrating the appendicular wall (Figure 1). On histological examination, this lesion was composed of a proliferation of spindle-shaped cells, without cytonuclear atypia. There was neither mitosis nor necrosis (Figure 2).

Immunohistochemestry showed expression of CD 34 and CD 117 in the tumor cells.

Hence, the diagnosis was a primary appendicular GIST.

The patient had no additional treatment after the final diagnosis and there were no symptom or complication at the last follow-up.

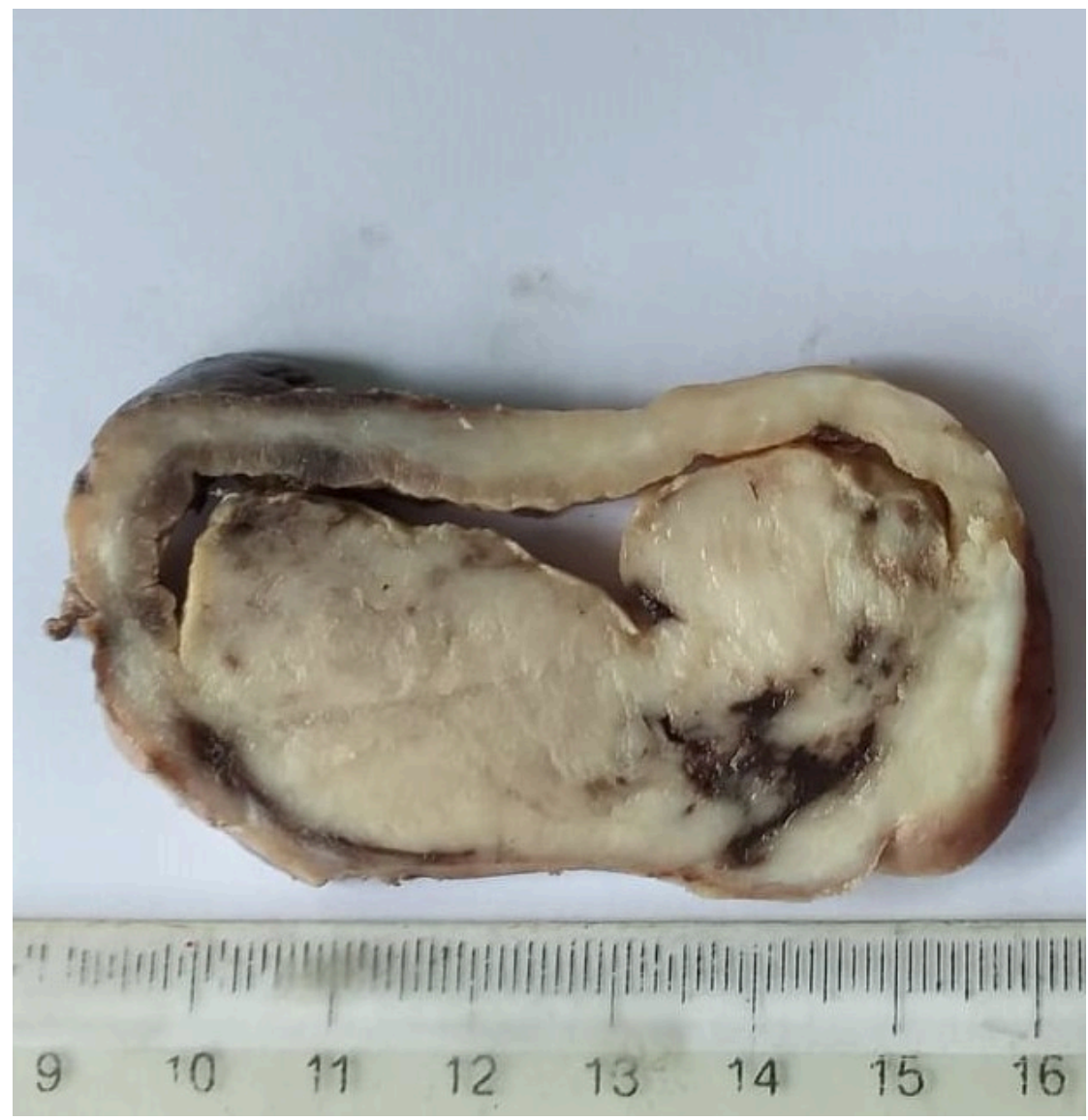

Source: Department of Pathology, Joseph Ravoahangy Andrianavalona University Hospital, Antananarivo.

Figure 1. Whitish and fasciculated mass, infiltrating one side of the appendicular wall. 


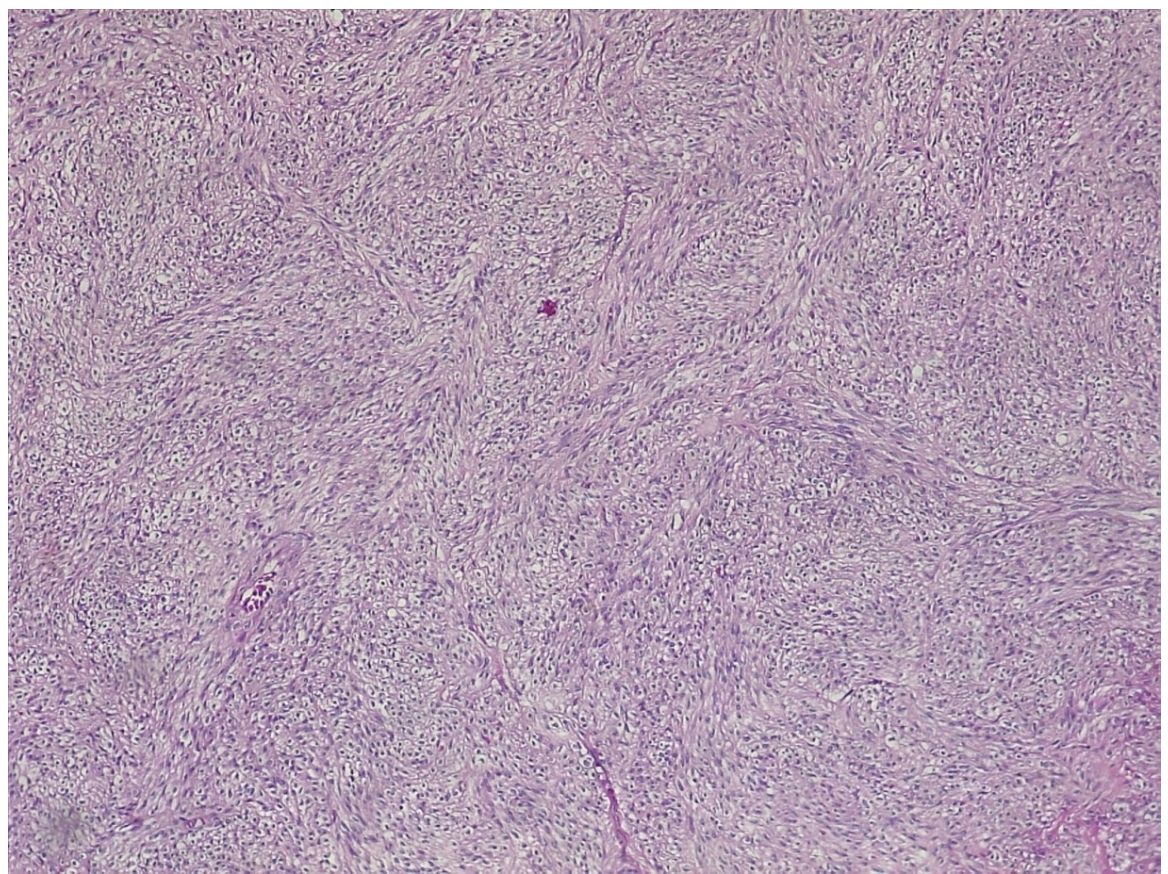

Source: Department of Pathology, Joseph Ravoahangy Andrianavalona University Hospital, Antananarivo.

Figure 2. Tumor characterized by proliferating spindle-shaped cells, without cytonuclear atypia. HE $\times 40$.

\section{Discussion}

GIST is an infrequent digestive mesenchymal tumor but the most common malignant mesenchymal tumor of the digestive tract $(0.2 \%$ of cancers of the digestive tract) [1]. Although described for more than 20 years, stromal tumors have been largely unrecognized [2]. The discovery in 1998 of the major oncogenic role of the receptor tyrosine kinase KIT in these tumors aroused particular interest in these tumors. Immunohistochemistry and genetics data have enabled the individualization of stromal tumors, which are now recognized as a distinct entity among mesenchymal tumors of the gastrointestinal tract.

GIST is most often localized in the stomach (55.6\%), then the small intestine (31.8\%), and rarely in the rectum and colon (6\%) [3]. According to the literature, the primary appendicular of GIST is extremely rare [4], represents $0.1 \%$ of cases [5].

Our patient was 48 years old at the time of diagnosis. The average age at the diagnosis is between 55 and 65 years old and this pathology are rare before the age of 40 and exceptional in children [6]. Bao Zhang et al. [7] found a median age of 59 years old with extremes of 7 and 88 years, among 24 cases of GIST appendicular.

There is no clear predominance of sex, only few studies found a male preponderance with a sex ratio close to 1.5 [8].

Most appendicular GIST are asymptomatic, discovered by surgery for other diseases or by autopsy, but sometimes it manifests with acute appendicitis-like 
symptoms complicated with peritonitis [9] as our case.

On gross examination, in our case, the tumor was solid, whitish, fasciculated, measuring $5 \mathrm{~cm}$ long. In the study by Bao Zhang et al. [7], the size of the $24 \mathrm{ap}$ pendicular GISTs varied from 1 to $10 \mathrm{~cm}$, of which $45.8 \%$ were less than $2 \mathrm{~cm}$. In the literature, the size of GISTs varies from $0.3 \mathrm{~cm}$ to $30 \mathrm{~cm}$ in diameter. It is one of the factors determining the malignant potential, less than $5 \mathrm{~cm}$, it has a low risk, greater than $10 \mathrm{~cm}$, the risk of malignancy is high [10]. GISTs develop in the thickness of the digestive wall, extending to the serous and/or mucosal side, and sometimes obstruct the lumen of the digestive tract when they are large. They may have an endophytic growth towards the digestive lumen ulcerating the mucosa, or exophytic towards the abdominal cavity, or mixed appearance [11].

Histologically, the tumor in our case was composed of spindle cells, without cytonuclear atypia, and without mitotic activity. The spindle feature represents $75 \%$ of GIST [11]. The cells are elongated, with a rounded or elongated central nucleus, with blunt tips. The chromatin is fine, dispersed and the nucleolus barely visible. The cytoplasm is eosinophilic, not very abundant. The cells arrange in spindle-shaped, sometimes with storiform or palisadic arrangement.

The differential diagnosis from other spindle cell tumors is important such as leiomyoma and schwannoma.

The cells can also be rounded "epithelioid type" in $20 \%$ of cases. Other cell types are more rarely seen: "signet-ring” cells, granular cells and multinucleated cells [11].

GIST exhibited a mutation of c-KIT gene and less frequently of PDGFR. In the $5 \%$ of GISTs, there is no expression of CD 117 on immunohistochemistry, genetic examination is indicated [12].

\section{Conclusion}

Pain in the right iliac region is often equated with acute appendicitis, with inflammatory origin. The tumor origin is not often suspected, although, despite its rarity, appendicular GIST should not be overlooked. Its clinical presentation and its appearance on ultrasound are not specific. Histopathological examination plays a major role in its diagnostic management.

\section{Conflicts of Interest}

The authors declare no conflicts of interest regarding the publication of this paper.

\section{References}

[1] Nezha, T., Asmaa, N., Zineb, B., Nadia, B., Hassan, J., Souha, S. and Abdelatif, B. (2017) Gastrointestinal Stromal Tumors "GIST": Status and News Through Our Experience on 54 Cases and Review of Literature. The Pan African Medical Journal, 27, 165.

[2] Bucher, P. and Morel, P. (2008) Tumeurs Stromale Gastro-Intestinales. Revue Médicale Suisse, 4, 1567-1570. 
[3] Søreide, K., Sandvik, O.M., Søreide, J.A., Giljaca, V., Jureckova, A. and Bulusu, V.R. (2016) Global Epidemiology of Gastrointestinal Stromal Tumours (GIST): A Systematic Review of Population-Based Cohort Studies. Cancer Epidemiology, 40, 39-46. https://doi.org/10.1016/j.canep.2015.10.031

[4] Misdraji, J. and Graemecook, F.M. (2004) Miscellaneous Conditions of the Appendix. Seminars in Diagnostic Pathology, 21, 151-163.

https://doi.org/10.1053/j.semdp.2004.11.006

[5] Miettinen, M. and Lasota, J. (2006) Gastrointestinal Stromal Tumors: Pathology and Prognosis at Different Sites. Seminars in Diagnostic Pathology, 23, 70-83. https://doi.org/10.1053/j.semdp.2006.09.001

[6] Miettinen, M. and Lasota, J. (2001) Gastrointestinal Stromal Tumors: Definition, Clinical, Histological, Immunohistochemical and Molecular Genetic Features, and Differential Diagnosis. Virchows Archiv, 438, 1-12. https://doi.org/10.1007/s004280000338

[7] Zhang, B., Zheng, G.L., Zhu, H.T., Zhao, Y. and Zheng, Z.C. (2018) Clinicopathological Characteristics and Prognosis of Primary Appendiceal Stromal Tumors. World Journal of Surgical Oncology, 16, Article No. 225225. https://doi.org/10.1186/s12957-018-1524-1

[8] Ösgus, H. and Yilmazlar, T. (2005) Analysis of Prognostic and Immunohistochemical Factors in GIST with Malignant Potential. Journal of Gastrointestinal Surgery, 9, 418-424. https://doi.org/10.1016/j.gassur.2004.07.003

[9] Miettinen, M. and Sobin, L.H. (2001) Gastrointestinal Stromal Tumors in the Appendix: A Clinicopathologic and Immunohistochemical Study of Four Cases. The American Journal of Surgical Pathology, 25, 1433-1437. https://doi.org/10.1097/00000478-200111000-00013

[10] Rubin, B.P. (2009) Gastrointestinal Stromal Tumors: An Update. Histopathology, 48, 83-96. https://doi.org/10.1111/j.1365-2559.2005.02291.x

[11] Bouzourene, H. (2009) Rôle du pathologiste dans la prise en charge des tumeurs stromales gastro-intestinales (GIST). Revue Médicale Suisse, 5,1505-1507.

[12] Doucet, L. (2006) Définition, données récentes en anatomopathologie et biologie moléculaire des tumeurs stromales gastro-intestinales. Bull Cancer, 93, S157-165. 